\title{
Effect of Zeolite-Fe on graphite anode in electroactive biofilm development for
}

\section{application in microbial fuel cells}

\author{
Thaís González ${ }^{1}$, M. S. Ureta-Zañartu², J. F. Marco ${ }^{3}$ and Gladys Vidal ${ }^{1}$
}

${ }^{1}$ Environmental Engineering \& Biotechnology Group, Environmental Science Faculty \& EULACHILE Center, Universidad de Concepción, Concepción, Chile.

${ }^{2}$ Departamento de Ciencias del Ambiente, Facultad de Química y Biología, Universidad de Santiago de Chile. C. Libertador Bernardo O’Higgins 3363, Estación Central, Santiago, Chile.

${ }^{3}$ Instituto de Química Física “Rocasolano”, CSIC, C. Serrano, 119, 28006-Madrid, Spain.

Submitted to: Applied Surface Science

Running title: Effect of Zeolite-Fe on graphite anode in electroactive biofilm development for application in microbial fuel cells.

(*) Corresponding author: Dr. Gladys Vidal

E-mail: glvidal@udec.cl

Telephone: 56-41-2204067

Fax: 56-41-2207076 


\section{Abstract}

The performance of microbial fuel cells (MFCs) is highly dependent on the electrode materials. The electrode surface can be modified to provide a favorable environment for biofilms to enhance electron transfer from the bacteria to the anode. In this work, Faujasite zeolite-Y (ZY) was exchanged with iron (Fe) and was used to modify glassy carbon/graphite electrodes $\left(\mathrm{GC} / \mathrm{gr}-\mathrm{Z} \mathrm{Y}_{\mathrm{Fe}}\right)$ evaluating its effect in electroactive biofilm development for application in microbial fuel cells. The novel material was evaluated as an anode in MFCs by comparing its performance with GC/gr and GC/gr-ZY electrodes. The results show that when using a $\mathrm{GC} / \mathrm{gr}-\mathrm{ZY} \mathrm{Y}_{\mathrm{Fe}}$ electrode, an electroactive biofilm with good electrochemical activity for acetate degradation can be generated on the electrode surface. The maximum current density obtained with a $\mathrm{GC} / \mathrm{gr}^{-} \mathrm{ZY}_{\mathrm{Fe}}-\mathrm{BF}$ electrode (where $\mathrm{BF}$ is biofilm) was 7.7 times higher than that of a GC/gr anode. The modification generates a less hydrophobic electrode surface that facilitates microbial cell attachment, thereby improving bioelectricity production. By using scanning electron microscopy, a homogeneous microbial community with bacteria that had a similar short rod-shaped morphology was observed. Furthermore, electrochemical impedance spectroscopy demonstrated that the charge transfer resistance $\left(\mathrm{R}_{\mathrm{ct}}\right)$ decreased as the biofilm grew, revealing that the presence of the biofilm facilitated the electrochemical reaction. After 7 days of MFC operation, the $\mathrm{GC} / \mathrm{gr}-\mathrm{ZY} \mathrm{Ye}_{\mathrm{Fe}}$ bioanode showed a reduction in $\mathrm{R}_{\mathrm{ct}}$ from $212.9 \pm 1.81 \Omega$ to $151.5 \pm 1.46 \Omega$, which was 2.4 times lower than that achieved with GC/gr. The biofilm on $\mathrm{GC} / \mathrm{gr}-\mathrm{ZY}_{\mathrm{Fe}}$ was characterized using cyclic voltammetry, and the results showed a larger oxidation peak $\left(169.8 \mu \mathrm{A} \mathrm{cm}^{-2}\right)$ than that of the GC/gr electrode $\left(36.5 \mu \mathrm{A} \mathrm{cm} \mathrm{cm}^{-2}\right)$, further supporting the better electron-transfer properties of the modified electrode. Additionally, this result confirms the capability of biofilms to act as bioelectrocatalysts under acetate-oxidizing conditions. 
Keywords: microbial fuel cell; anode modification; zeolite Y; biofilm growth; electrochemical characterization. 


\section{INTRODUCTION}

Microbial fuel cells (MFCs) are bioelectrochemical devices that convert inorganic and organic waste into electricity using microorganisms as catalysts [1]. The anode is the site where a biocatalyst grows in the form of a biofilm, which promotes the decomposition of biomass to produce electrons and protons. For this reason, the characteristics of the electrode surface crucially affect the bacterial attachment and electrical connection between the bacteria and the electrode surface.

An ideal anodic material must be stable and biocompatible to promote microbial adhesion and biofilm formation; the material must also be conductive to facilitate the transfer and flow of electrons, thus promoting the electron transfer reaction rate on the electrode surface $[2,3]$. Materials commonly used as anodes include commercial carbon-based electrodes, such as graphite rods, granular activated carbon, graphite felt and carbon cloth [4, 5]. To improve the anode performance, other types of non-conventional carbonaceous materials such as graphene, carbon nanotubes, conducting polymers, composites and metal oxides have also been developed as electrodes [6-9].

The electrode surface can be modified to become favorable environments for biofilm growth, taking advantage of the film's ability to enhance electron transfer (ET) from the bacteria to the anode surface, thus achieving more efficient anodes. Different surface modification technologies have been developed, such as doping, coating and functionalizing the electrode surface with different materials [10]. An important aspect to consider regarding the electrode surface is its degree of hydrophobicity or hydrophilicity. An increase in hydrophilicity can be expected if the electrode surface is modified with transition metal oxides due to the presence of $\mathrm{OH}$ groups and adsorbed water or a hydroxide anion. Quiao et al. [11] modified a carbon fiber anode with $\mathrm{NiO}$ scales, whereby the electrode surface became more hydrophilic, thus improving the microbial adhesion to the electrode surface 
and directly increasing the electron transfer through the outer membrane and the cytochrome at the anode surface. The authors related this result to the wettability of these surfaces. Fu et al. [12] developed carbon nanotube multilayers with $\mathrm{MnO}_{2}$ (50\% by weight) and reported that the mixed anodes facilitated greater wettability than the electrodes without metal oxides. The increase in wettability improves the reaction rate and increases the power density of MFCs.

A simple and inexpensive method to alter the hydrophobicity of different electrodes is coating their surface with a graphite-zeolite mixture to increase the electrode's real surface area and to generate a change in its hydrophobic-hydrophilic characteristic. Zeolites are a special type of microporous alumino silicate with a three-dimensional structure that extends infinitely in the crystalline lattice [13]. Zeolites are composed of tetrahedrally bonded aluminum oxides $\left(\mathrm{AlO}_{4}\right)$ and silicon oxides $\left(\mathrm{SiO}_{4}\right)$ sharing a bond with an oxygen atom. Although these materials have been used in electrochemical cells [14], their application to MFCs has only been reported by $\mathrm{Wu}$ et al. [15]. The authors hydrothermally modified graphite electrodes from a $\mathrm{NaX}$ zeolite solution. This $\mathrm{NaX}$ zeolite is hydrophilic ( $\mathrm{Si} / \mathrm{Al}$ ratio of $\sim 1.5$ ), which decreases the hydrophobicity of graphite. The authors reported that the results showed a maximum power density and coulomb efficiency of $152 \%$ and $36 \%$, respectively, which are higher values than those obtained with unmodified anodes. The improvement in the yield of the MFC was attributed to a super-hydrophilicity characteristic that was generated due to modification of the anode with zeolite. According to the authors, $\mathrm{NaX}$ zeolite promotes this super-hydrophilicity characteristic by forming a thick biofilm, which accelerates the anodic bioelectrochemical reactions.

Alternatively, iron oxides have been used to modify carbon electrodes to increase electron transfer, which occurs due to the high biocompatibility and specific affinity of the outer cell membrane to the bacterial proteins. It was reported that an electrode coated with iron oxides 
had an approximately 4-fold higher power generation in a MFC that was inoculated with a mixed culture [16]. A great variety of natural and synthetic zeolites exist with different levels of hydrophobicity, and they can be interchanged with transition metals. For example, the Faujasite is a commercial synthetic zeolite with a $2.5 \mathrm{Si} / \mathrm{Al}$ ratio, cage structure formed by 12 rings and inner channel system of $7.4 \AA$ x $7.4 \AA$. It has medium hydrophilicity, so is expected to decrease the hydrophobicity of the GC/graphite surface facilitating biofilm formation on the electrode surface, which leads to an improvement in the electron transfer across the anode; thus, the objective of this work is to modify GC electrodes with a mixture of graphite-ZY exchanged with Fe (GC/gr-ZYFe) and to evaluate its effect in electroactive biofilm development for application in microbial fuel cells. GC electrodes coated with a film of gr-ZYFe were used as anodes and the performance was evaluated through comparison with that of the GC/gr and GC/gr-ZY electrodes.

\section{MATERIALS AND METHODS}

\subsection{Zeolite-Y modification and characterization}

Faujasite zeolite (ZY), provided by Aldrich, St. Louis, USA, was used as received. ZY was exchanged with Fe(III) cations (Iron doped zeolite) according to the literature [17]. Briefly, $3.0 \mathrm{~g}$ of $\mathrm{ZY}$ and the corresponding amount of $\mathrm{Fe}\left(\mathrm{NO}_{3}\right)_{3} \bullet 9 \mathrm{H}_{2} \mathrm{O}($ Merk $>99 \%)$ required for obtaining a metal loading of $6 \mathrm{wt} . \%$ were suspended and dissolved in $60 \mathrm{~mL}$ of double bidistilled water. The mixture was stirred at room temperature for 1 hour in a rotary evaporator until it was dry. To remove the Fe(III) that was not exchanged with the ZY, the mixture was washed repeatedly with $1 \mathrm{M}$ and $0.1 \mathrm{M} \mathrm{KCl}$ solutions, centrifuged and dried in an oven (Trade RAIPAR®) at $105^{\circ} \mathrm{C}$ overnight.

The modified zeolite was characterized using an X-ray photoelectron (XPS) CLAM2 electron analyzer in a vacuum at a pressure greater than $5 \cdot 10^{-9}$ mbar, with a take-off angle of $90^{\circ}$ using $\mathrm{Mg} \mathrm{K} \alpha$ radiation. A constant pass energy of $200 \mathrm{eV}$ was used to record the wide- 
scan spectra, whereas narrow-scan spectra were recorded using a pass energy of $20 \mathrm{eV}$. The binding energy scale was referenced to the main $\mathrm{C} 1 \mathrm{~s}$ signal of the adventitious contamination layer, which was set at $284.6 \mathrm{eV}$.

The specific surface area of the anodes was evaluated using the Brunauer-Emmett-Teller (BET) surface areas $\left(\mathrm{S}_{\mathrm{BET}}\right)$, and mesopore $\left(\mathrm{V}_{\mathrm{m}}\right)$, micropore and total pore $\left(\mathrm{V}_{\text {total }}\right)$ volumes, which were determined by nitrogen adsorption-desorption isotherms at $77 \mathrm{~K}$ using a Micromeritics Tristar II instrument.

The morphology of the zeolites and the anodes was characterized by SEM with an ETEC Autoscan 490 LV coupled with energy-dispersive X-ray spectroscopy (EDS). FTIR-ATR Spectroscopy with a Bruker-Platinum-ATR instrument was used as a chemical characterization tool.

\subsection{Electrode preparation and physicochemical characterization of the anode}

In a previous work, the graphite-zeolite electrodes were optimized the graphite-zeolite electrodes in terms of their resistance to charge transfer, considering that the zeolites are not conductive. The optimum value determined was $20 \% \mathrm{ZY}$ in graphite [18]. Regarding the content of Fe in aluminosilicates, the optimal results were found with Fe at 6 wt. \% [19, 20].

A $\mathrm{ZY}_{\mathrm{Fe}}$-graphite suspension was prepared as previously reported [18] (including $50 \mathrm{mg}$

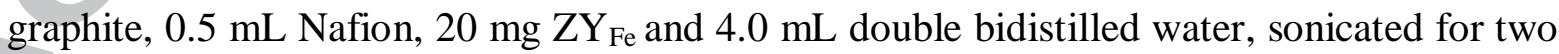
hours), and $50 \mu \mathrm{L}$ was collected to be deposited on the surface of a serigraph glassy carbon (GC) electrode (Dropsens 110). The solvent was evaporated in a stove at $60^{\circ} \mathrm{C}$ for $30 \mathrm{~min}$. GC electrodes coated with graphite and graphite-unexchanged ZY were used as controls. Finally, the GC/gr-ZY $\mathrm{Fe}$, GC/gr-ZY and GC/gr electrodes were stabilized by repetitive cyclic voltammetry $(\mathrm{RCV})$ at $0.1 \mathrm{~V} \mathrm{~s}^{-1}$ for 10 scans in phosphate buffered saline (PBS, $\mathrm{pH}$ 7.4) electrolyte. The real area of the electrode (Rugosity factor, $R_{F}$ ) was determined using 
the method described by Trasatti et al. [21] for graphite electrodes, with the variant proposed by Fernández et al. [18] for graphite-zeolite electrodes. The method includes the determination of the double layer capacity by $\mathrm{CV}$ at different scan rates (10, 30, 50 and 100 $\mathrm{mV} \mathrm{s}^{-1}$ ), only in the potential range associated with the charge/discharge of the double layer $(-0.6 \mathrm{~V}$ to $+0.6 \mathrm{~V}$ vs. $\mathrm{Ag} / \mathrm{AgCl})$. The slope of a plot of the capacitive current density $\left(\mathrm{j}_{\mathrm{dl}}\right)$ against the potential scan rate (v) corresponds to the double layer capacity. The reference value for the double layer capacitance was obtained using a mirror-polished GC electrode $(\mathrm{CHI})$ and is considered a unit roughness factor reference, $\mathrm{C}^{\circ}$. Modified electrodes have areas over 20 times greater than the GC electrode that was used as a reference.

\subsection{MFC construction, inoculation and operation}

For the formation of the biofilm, the experiments were carried out in triplicate. The system consisted of two compartment glass cells, separated by a glass key that is kept wet to allow the flow of ions. The volume of each compartment was $100 \mathrm{~mL}$ and a distance of $10 \mathrm{~cm}$ between the electrodes. MFCs with modified GC electrodes $\left(0.130 \mathrm{~cm}^{2}\right.$ geometric area) as the anode material (working electrode) and Pt (spiral, large area) as the cathode were prepared, and their electrochemical behavior was determined. The anodes include graphite (GC/gr), graphite-zeolite (GC/gr-ZY) and graphite-iron-exchanged zeolite (GC/gr-ZY $\mathrm{Fe})$. The anode was connected through an electrical resistance of $100 \mathrm{ohms}$ with the cathode during the inoculation process. The anodic compartment was inoculated with a mixed sludge. This mixture contained $50 \%$ primary clarifier (Primary treatment) and $50 \%$ activated sludge (Secondary treatment) from the domestic wastewater treatment plant (Concepción, Chile) and were fed with a growth medium containing $\mathrm{CH}_{3} \mathrm{COONa}\left(0.82 \mathrm{~g} \mathrm{~L} \mathrm{~L}^{-}\right.$

${ }^{1}$ ) in $10 \mathrm{mM}$ PBS (pH 7.4; $1.44 \mathrm{~g} \mathrm{Na}_{2} \mathrm{HPO}_{4}, 0.24 \mathrm{~g} \mathrm{KH}_{2} \mathrm{PO}_{4}, 0.2 \mathrm{~g} \mathrm{KCl}$ and $8 \mathrm{~g} \mathrm{NaCl}$ up to a $1 \mathrm{~L}$ aqueous solution), $0.7 \mathrm{~g} \mathrm{~L}^{-1} \mathrm{NH}_{4} \mathrm{Cl}, 0.2 \mathrm{~g} \mathrm{~L}^{-1} \mathrm{CaCl}_{2}$, and $1 \mathrm{~mL} \mathrm{~L}^{-1}$ of a solution of trace elements (content per liter: $0.25 \mathrm{~g} \mathrm{FeCl}_{3} \bullet 6 \mathrm{H}_{2} \mathrm{O}, 0.15 \mathrm{~g} \mathrm{MgSO}_{4} \bullet 7 \mathrm{H}_{2} \mathrm{O}, 0.1 \mathrm{~g} \mathrm{H}_{3} \mathrm{BO}_{3}$ and $0.1 \mathrm{~g}$ 
$\mathrm{Na}_{2} \mathrm{MoO}_{4}$ ). The system was maintained under constant stirring using a magnetic stirrer. To ensure anaerobic conditions, the growth medium together with the inoculum were purged with nitrogen for $30 \mathrm{~min}$ prior to use. The cathode compartment was filled with $80 \mathrm{~mL}$ of PBS ( $\mathrm{pH}$ 7.4) and maintained with permanent aeration. The MFCs were operated at room temperature $\left(30{ }^{\circ} \mathrm{C} \pm 1{ }^{\circ} \mathrm{C}\right)$ in fed-batch mode for 7 days. The concentration of the acetate anion in the growth medium was controlled, remaining practically constant during the entire process. Each time that substrate depletion was observed (via a voltage decrease), $50 \mathrm{~mL}$ of solution was removed and replaced by the same volume of a new acetate-PBS solution.

\subsection{Electrochemical measurements}

Electrochemical measurements were performed with a CHInstruments 660-C workstation with a 3-electrode configuration, including a working electrode (the prepared anodes), a $\mathrm{Ag} / \mathrm{AgCl}$ reference electrode $\left(3 \mathrm{M} \mathrm{KCl}, \mathrm{E}^{\circ}=0.194 \mathrm{~V}\right.$ vs. SHE$)$ and a large-area Pt coil as a counter electrode. The electrodes were characterized by $\mathrm{CV}$ at $5 \mathrm{mV} \mathrm{s}{ }^{-1}$ with a potential range between $-0.8 \mathrm{~V}$ and $+0.6 \mathrm{~V}$, in $10 \mathrm{mM}$ PBS (pH 7.4) with and without sodium acetate in a one-compartment cell, before inoculation and after the biofilm was formed. All current density values were normalized by the anode geometric area, using the corresponding $\mathrm{R}_{\mathrm{F}}$ value given in the figure caption. The electrodes were also characterized using electrochemical impedance spectroscopy (EIS) at a constant potential (-0.2 V vs. $\mathrm{Ag} / \mathrm{AgCl})$ using a sinusoidal modulation of $5 \mathrm{mV}$ in a frequency range of $10 \mathrm{kHz}$ to $10 \mathrm{mHz}$, with a logarithmic decrease of frequency, with 12 points per decade. The analysis of the impedance spectra was performed with the NOVA 2.1 program. Chronoamperometic curves were obtained at a controlled potential $\left(\mathrm{E}_{\mathrm{Ag} / \mathrm{AgCl}}=+0.3 \mathrm{~V}\right)$ for 80 min to investigate the electrochemical behavior of the system.

\subsection{Preparation and characterization of the biofilms}


The biofilms were set according to the methodology reported by Zhang et al. [22] in a $2.5 \%$ glutaraldehyde solution in $0.1 \mathrm{M}$ PBS ( $\mathrm{pH} 7.4$ ) for 12 hours at $4{ }^{\circ} \mathrm{C}$. The biofilms were then dewatered at increasing concentrations of ethanol (30, 50, 80, 90 and 100\%). Finally, the samples were dried to a critical point with $\mathrm{CO}_{2}$. The samples were fixed to a metallic support with double-sided carbon tape and coated with a thin layer of gold for immediate observation using SEM. The degree of homogeneity of the biofilms was determined.

\section{RESULTS AND DISCUSSION}

\subsection{Characterization of zeolite modified with iron}

The SEM image of the as received ZY zeolite is shown in Figure 1A. The zeolite shows a homogeneous morphology with a crystal structure of granular type. It is composed of agglomerates cubes and single particles on the order of $1.81 \pm 0.34 \mu \mathrm{m}$ on the diagonal and $0.85 \pm 0.12 \mu \mathrm{m}$, respectively. The presence of Fe (Figure 1B) does not modify the structure of the zeolite. The SEM showed no changes in the morphology or in the size of particles. For EDS, it was estimated that the composition of Fe was 5.1 wt. \% (2.47 atomic \%). The unmodified $\mathrm{ZY}$ has $6 \%$ at/at of $\mathrm{Na}$ and $0 \% \mathrm{~K}$, whereas in $\mathrm{ZY}-\mathrm{Fe}$ near to $2.88 \%$ in $\mathrm{Na}$ and $2.47 \%$ in Fe was observed. No K was detected.

Figure 1

The wide-scan XPS spectrum recorded from the original ZY is presented in Figure 2 (curve a), revealing, as expected, the contributions of $\mathrm{Al}, \mathrm{Si}$ and $\mathrm{O}$ plus the typical $\mathrm{C}$ signal due to an adventitious carbon layer. In addition, intense peaks are observed at $260 \mathrm{eV}$ and 296/380 $\mathrm{eV}$, which correspond to the presence of $\mathrm{Na}$ and $\mathrm{K}$, respectively. The presence of $\mathrm{Na}$ and $\mathrm{K}$ is likely due to the charge compensation cations that in the zeolite structure. The wide-scan spectrum recorded from the iron-exchanged ZY is also presented in Figure 2 (curve $b$ ). It is interesting to note that this spectrum contains iron signals and that the $\mathrm{Na}$ and $\mathrm{K}$ peaks that were present in the original zeolite have now disappeared, indicating that these cations have 
characteristics bands associated to the presence of water and/or hydroxyls groups (3000$4000 \mathrm{~cm}^{-1}$ and $\left.2330 \mathrm{~cm}^{-1}\right)$. The wide main peak to $\left(991 \mathrm{~cm}^{-1}\right)$ has been attributed to the asymmetric and symmetric stretching modes of internal tetrahedra. The ZY-Fe spectra (curve 2) presents all the original peaks of ZY without shifted, implying that no formation of new bonds. The more intense band of the zeolite is increased with iron due to the iron oxides have a characteristic signal at $990 \mathrm{~cm}^{-1}$. The signal at $1300-1400 \mathrm{~cm}^{-1} ; 780-716 \mathrm{~cm}^{-1}$ and 453 $\mathrm{cm}^{-1}$ are characteristics of different structures of iron oxide. In summary, the method used for modified ZY does not affect the framework of this, as was observed in Fig.3

\section{Figure 3}

\subsection{Formation and growth of the biofilm}

Figure 4 shows the cell output voltage of GC/gr, GC/gr-ZY and GC/gr-ZYFe generated during MFC operation for the biofilm formation. The maximum voltages for GC/gr electrode varied between $0.481 \pm 0.076 \mathrm{~V}$ and $0.535 \pm 0.110 \mathrm{~V}$ until day 4 . In the last batch the voltage slightly increased to $0.582 \mathrm{~V} \pm 0.031$ being $12.1 \%$ and $18.3 \%$ lower compared to GC/gr-ZY and GC/gr-ZYFe, respectively. On the other hand, a relatively minor difference among voltages of the GC/gr-ZY and GC/gr-ZYFe electrodes tested was observed during the first 4 feeding cycles. From the fifth cycle the GC/gr-ZYFe presents the highest performance with a stable maximum voltage of $0.718 \pm 0.015 \mathrm{~V}$, which was $10.5 \%$ higher than that of the MFC with GC/gr-ZY electrode $(0.653 \pm 0.018 \mathrm{~V})$.

\section{Figure 4}

The effective colonization of the electrodes after 7 days of operating the MFCs was determined by transferring the biofilm-coated electrode to an electrochemical cell containing $10 \mathrm{mM}$ acetate anions in PBS, for which the recorded current evolution was $80 \mathrm{~min}$. The responses of the three electrodes (GC/gr, GC/gr-ZY and $\mathrm{GC} / \mathrm{gr}-\mathrm{ZY}_{\mathrm{Fe}}$ ) with formed biofilms ( $a, b$ and $c$, respectively) and the control electrode without the biofilm (curve $d$ ) are shown 
in Figure 5. The presence of a biofilm is evidenced for zeolite-based electrodes by a stabilized current over $0.1 \mathrm{~mA} \mathrm{~cm}{ }^{-2}$ that is obtained between $60 \mathrm{~min}$ and $80 \mathrm{~min}$. The current density was very similar for zeolite-based electrodes with values of $0.144 \pm 5.12 \times 10^{-7} \mathrm{~mA}$ $\mathrm{cm}^{-2}$ and $0.152 \pm 7.64 \times 10^{-7} \mathrm{~mA} \mathrm{~cm}{ }^{-2}$ for GC/gr-ZY and GC/gr-ZY $\mathrm{Fe}$, respectively.

When the same experiment was performed using $\mathrm{ZY}_{\mathrm{Fe}}$ a maximum was observed at 25 min, which then decreased until reaching the same observed stationary value for the sample without Fe (curve c). As expected, in the absence of a biofilm, no change in the current was observed (curve d), whereas in the absence of ZY (only for the GC/graphite electrode), the current increase was almost insignificant (curve a). For curves $b$ and $c$, the maximum stable current was 7.7 times higher than that of the $a$-curve. These results imply that a bacterial film grew over the electrode surface and that this film presented catalytic activity for the degradation of organic matter. In addition, the system acted as a source of electrons injected into the external circuit, thus generating an electric current. The plausible explanation for the effect of zeolite when it is in a mixture with graphite supports our hypothesis, namely, that the zeolite mixture decreases the hydrophobicity of the electrode surface and improves the surface wettability. This property is related to the electrochemical reaction because it is one of the most important factors determining cell adhesion behavior. The presence of Fe can be considered an anchor point that facilitates the transfer of electrical charge and furnishing ZY and the Fe center together provides a better environment for biofilm growth. Finally, the stability of GC/gr-ZYFe with respect to the generation of electricity was checked by chronoamperometry (at $+0.2 \mathrm{~V}$ vs. $\mathrm{Ag} / \mathrm{AgCl}$ ) after 2 days have finished the stage of biofilm formation (Inset Fig.4). The current density was remained constant during the last $140 \mathrm{~min}$ with an average value of $2.03 \times 10^{-5} \pm 8.5 \times 10^{-7} \mu \mathrm{A} \mathrm{cm}^{-2}$.

Figure 5

\subsection{Biofilm characterization}




\subsubsection{Morphological characterization of biofilms}

The SEM images (Figure 6) show the surfaces of GC/gr (A), GC/gr-ZY (B) and GC/gr-ZY $\mathrm{Fe}_{\mathrm{f}}$ (C) before and after 7 days of MFC operation (D, E and F, respectively). Initially, the electrode surfaces have an irregular topography formed by non-porous GC flakes of different sizes (Figure 6A), as well as some cubical particles of ZY (inside the circle) (Figure 6B and 6C). The EDS analysis confirms the presence of $\mathrm{ZY}$ and $\mathrm{ZY} \mathrm{Fe}_{\mathrm{Fe}}$ in micrographs B and C, especially in the agglomerations and granules that are lighter in color. In agreement with Figure 1, no differences attributable to the presence of iron are observed by SEMS-EDS. The GC electrode is coated with a homogeneous thin film of graphite and zeolite, as expected. The formation of a biofilm is evidenced in the micrographs obtained after 7 days of MFC operation (Figure 6 D-F), where a drastic change is observed in the electrode surface. At this time, there is a non-uniform film deposited on the GC flakes, revealing the presence of the biofilm. The biofilm coats the entire surface as a rough and porous mantle, as observed in the SEM images in which the original GC flakes are coated on all sides with the biofilm. The biofilm morphology exhibited similar characteristics in the three anodes, with diverse sizes and shapes of microorganisms, which are mostly rod-shaped and embedded in extracellular polymeric substances. The SEM images of the biofilms agree with the electrochemical response shown in Figure 5 because the electrode with higher effective currents has a film richer in microorganisms. Therefore, with respect to the electrode surface used in the formation of the biofilm, the effectiveness in the presence of bacteria on the electrode surface is in the order of $\mathrm{GC} / \mathrm{g}-\mathrm{ZY} \mathrm{Fe}_{\mathrm{Fe}}>\mathrm{GC} / \mathrm{g}-\mathrm{ZY}>\mathrm{GC} / \mathrm{g}$ (Figs. 6D, $\mathrm{E}$ and $\mathrm{F}$ ). Thus, the $\mathrm{GC} / \mathrm{g}-\mathrm{ZY} \mathrm{Fe}_{\mathrm{Fe}}$-biofilm has a greater number of active sites on its surface. The results observed are in total agreement with our hypothesis in that the hydrophilic characteristic of the zeolite ZY facilitates the access of the bacteria to the electrode/electrolyte interface, enabling the electron transfer with graphite to form the 
biofilm. The presence of iron, on the other side, plays an important role and probably facilitates the electron transport. According to the references [26-28], the bacteria that are adhered to these anodes could belong to the genus Shewanella and Geobacter because in studies of MFCs with pure strains, similar forms have been reported. It should be noted that the entire procedure was performed in triplicate, and the observed behaviors were all very similar.

\section{Figure 6}

\subsubsection{Electrochemical behavior of anodes coated with a biofilm}

Two aspects are fundamental in the electrochemical study of the behavior of biofilm anodes: the stability of the film and the electrical transport through it.

$\mathrm{CV}$ is typically used to analyze the electrochemical stability in these systems [27, 30 29-32]. Figure 57 compares the $\mathrm{CV}$ results obtained at $5 \mathrm{mV} \mathrm{s}^{-1}$ in a PBS $\mathrm{N}_{2}$-saturated electrolyte with the GC/gr, GC/gr-ZY and GC/gr-ZY $\mathrm{Fe}_{\mathrm{Fe}}$ electrodes in the absence (thin line) and the presence (thick line) of a biofilm. The results are representative of the experiments that were developed in triplicate. The potential scan starts from the open circuit potential (OCP) in the positive direction (see the arrow), until $0.6 \mathrm{~V}$, after which the scan rate direction is reversed down to $-0.8 \mathrm{~V}$, ending the cycle at the positive potential. In the absence of a biofilm, the three working electrodes used show a large reduction peak (1c) near $-0.3 \mathrm{~V}$ associated with the oxygen reduction reaction (ORR) (probably occluded in the graphite pores) and/or a quinone-/hydroquinone-like process, which is characteristic of the keto groups on the graphite surface (process 1a/1c, Figure 7). At a more negative potential, a new reduction process is observed, probably associated with hydrogen adsorption, previous step in the evolution reaction (HER) (peak 2c, Figure 7). Note that the electrode based on $\mathrm{ZY}_{\mathrm{Fe}}$ shows an increase in the current density of the double layer region, which is not attributable to a higher $\mathrm{R}_{\mathrm{F}}$ value $\left(\mathrm{R}_{\mathrm{F}}\right.$ values are 13.8, 22.6 and 25.4 for $\mathrm{GC} / \mathrm{gr}, \mathrm{GC} / \mathrm{gr}-\mathrm{ZY}$ and $\mathrm{GC} / \mathrm{gr}-\mathrm{ZY} \mathrm{Y}_{\mathrm{Fe}}$, 
respectively) or an increase in the ohmic resistance. This result may be due to the poorly defined $\mathrm{Fe}(\mathrm{III}) / \mathrm{Fe}(\mathrm{II})$ processes. It has been reported that the species based on $\mathrm{Fe}$ do not have a single type of interaction with the electrode surface [18].

\section{Figure 7}

The voltammetric profiles change drastically when the electrode is coated with a biofilm. The $1 \mathrm{C}$ peak decreases, revealing that the graphite surface is not directly exposed to the electrolyte, and anodic currents are observed. Three anodic processes are defined, and none can be directly attributed to the process 1 a observed in the bare electrode. The anodic currents are higher using the electrode based on $\mathrm{ZY}_{\mathrm{Fe}}$, where an abrupt increase in intensity, associated with process $4 \mathrm{a}$, is observed. This finding prompts the question of whether there could be a redox process between the biofilm and the species of $\mathrm{Fe}(\mathrm{III})$, which would regenerate by applying an electric potential. This occurs when the metal center serves as a redox mediator, as with the $\mathrm{Fe}(\mathrm{HI}) / \mathrm{Fe}(\mathrm{II})$ redox couple. The HER (peak 2c in Figure 7) is shifted to a less positive potential, indicating that the biofilm-modified electrode surface decreases the hydrogen overvoltage, mainly in the presence of $\mathrm{ZY}$ and $\mathrm{ZY} \mathrm{Ye}_{\mathrm{Fe}}$, which is in agreement with the results reported by Marsilli et al. [31]. The CV results fully agree with the observations in Figures 5 and 6 in that the biofilms obtained on electrodes with ZY are homogeneous and have a larger number of active sites. In addition, the CV results indicate the presence of several active redox species whose responses are overlapped due to the nature of the mixed culture that was used for biofilm growth, especially on the GC/gr-Z $\mathrm{Y}_{\mathrm{Fe}}$ electrode, where a significant increase of current in the zone of Fe(II) oxidation potentials is observed. Therefore, the redox couple $\mathrm{Fe}(\mathrm{III}) / \mathrm{Fe}(\mathrm{II})$ acts as a redox mediator, playing the same role as typical biomolecules, such as flavins [32], the cytochrome c outer membrane, OmcA [33], OmcB [34], OmcZ [35] and MtrC [36], which are known to participate in the transfer of electrons by bacteria towards solid electrodes. 
The most suitable electrochemistry technique to gain information about electrical transport is EIS [37-38]. Therefore, EIS experiments were performed to determine how the properties of electric charge transport are modified depending on the biofilm thickness. The results are shown in Figure 8 as a Nyquist plot for the $\mathbf{G C / G r}$ (curve 1), • GC/gr-ZY (curve 2) and $\Delta \mathrm{GC} / \mathrm{gr}-\mathrm{ZY} \mathrm{Y}_{\mathrm{Fe}}$ (curve 3) electrodes as a function of growth time over 0 (A), 4 (B) and 7 (C) days. According to the Randles equivalent circuit, the characteristic semicircle can be interpreted as an uncompensated resistance $\left(\mathrm{R}_{\mathrm{s}}\right)$ in a series with a circuit formed by a charge transference resistance $(\mathrm{Rct})$ in parallel with a capacitor (double layer capacitance, $\mathrm{C}_{\mathrm{dl}}$ ). According to the results shown in the Nyquist plots (Figure 8), it is necessary to change the capacitor by a constant phase element (CPE). Thus, the equivalent circuit $\mathrm{R}_{\mathrm{s}}-\mathrm{R}_{\mathrm{ct}} / \mathrm{CPE}$ (Figure 9) was used in the equivalent circuit for software simulation using Nova 2.1 software. The results shown in Table 2 indicate that the $R_{\mathrm{s}}$ values increase according to $\mathrm{GC} / \mathrm{g}-\mathrm{ZY} \mathrm{Fe}_{\mathrm{Fe}}>\mathrm{GC} / \mathrm{g}-\mathrm{ZY}>\mathrm{GC} / \mathrm{g}$, whereas the Faraday resistance decreases in the same order, according to the role of $\mathrm{ZY}$ and $\mathrm{ZY}_{\mathrm{Fe}}$ in the charge transfer process. At the end of the incubation process, the uncompensated resistance was very similar, in accordance with the fact that the resistance of the electrolyte remained nearly constant. However, the $R_{c t}$ parameters decreased noticeably with the biofilm thickness, which agrees with an increase in the numbers of charge carriers (transferred electrons) due to a higher reaction rate, as observed by CV. It is notable that once the biofilm is formed, the decrease in the $\mathrm{R}_{\mathrm{ct}}$ parameter is observed markedly in the presence of ZY. Accordingly, the decreases in the faradaic resistance with electrodes based on $\mathrm{ZY}_{\mathrm{Fe}}$ are higher, tending toward a lower $\mathrm{R}_{\mathrm{ct}}$ value in the presence of $\mathrm{Fe}$ at a longer incubation time. Note that $\mathrm{R}_{\mathrm{ct}}$ is inversely proportional to the exchange current density $\left(\mathrm{I}_{0}\right)$ of the reaction that occurs at the electrode surface. The capacitance of the anodes, evaluated as $\mathrm{C}=-1 /\left(\mathrm{Z}_{\mathrm{im}} \omega\right)$, is constant with the real impedance $\mathrm{Z}_{\text {Real }}$ and decreases slightly with the film growth. The capacitance against real 
impedance $\left(\mathrm{C}\right.$ vs $\mathrm{Z}_{\mathrm{Re}}$ plot in Figure $\mathrm{S} 2$ ) trend is interesting because the presence of a large capacitance of an electrode surface without a biofilm is typical for anodes with micro- and nano porosity (Figure S2A). This capacitance decreases with a short incubation time where the original surface has been coated with the biofilm (Figure S2B), and it increases again with a longer incubation time, revealing that the new surface is also porous (Figure S2C).

Figure 8

Figure 9

Table 2

\subsubsection{Catalytic activity of the biofilms}

The effectiveness of the bioelectrode as an anode for organic matter degradation, which is a process that must occur in a biocell, is determined by the catalytic activity for acetate anion degradation. The catalytic activity of $\mathrm{GC} / \mathrm{gr}-\mathrm{ZY} \mathrm{Fe}_{\mathrm{Fe}} \mathrm{BF}$ (an electrode coated with the biofilm) was evaluated using $\mathrm{CV}$ at $0.005 \mathrm{~V} \mathrm{~s}^{-1}$ in $10 \mathrm{mM} \mathrm{CH}_{3} \mathrm{COOH}$ with $\mathrm{PBS}$ as the electrolyte at pH 7.4 and compared with GC/gr-ZY-BF and GC/gr-BF under the same experimental conditions. The biofilm obtained on $\mathrm{GC} / \mathrm{g}-\mathrm{ZY} \mathrm{Fe}_{\mathrm{Fe}}$ shows a higher current density, although for the GC/g-ZY-BF anode, the acetate degradation begins at a low potential (Figure 10). For the electrodes without a biofilm (inset Figure 10), no redox peaks related to acetate oxidation were observed. The acetate anion only reacts on the electrode if it is coated with a biofilm; for this anode, the I/E profile is similar to those obtained in the absence of acetate anion (Figure 7). The only current density observed is that associated with the charge of the electrical double layer. The bacteria play a fundamental role, acting as the site where the heterogeneous electrons are transferred from the acetate anion to the anode. The peak current density is a good parameter to determine the number of active sites. The biofilm on the GC/gr-ZY (Figure 10, curve 2) and GC/gr-ZY Fe $($ Figure 10, curve 3) electrodes exhibited oxidation peaks with $135.4 \mu \mathrm{A} \mathrm{cm}^{-2}$ at $0.21 \mathrm{~V}$ and $169.8 \mu \mathrm{A} \mathrm{cm}^{-2}$ at $0.41 \mathrm{~V}$, respectively, 
which represent a $25 \%$ increase in the presence of iron species. The GC/gr biofilm (Figure 10, curve 1) also shows an anodic process at a less positive potential $(-0.41 \mathrm{~V})$, and the oxidation peak $\left(36.5 \mu \mathrm{A} \mathrm{cm}{ }^{-2}\right)$ was smaller than that of the gr-ZY and gr-ZY $\mathrm{Fe}_{\mathrm{Fe}}$ electrodes. The weak peak current was probably caused by the lower number of microbial cells attached to the graphite material. A higher peak current density indicates more electrochemical activity, possibly meaning improvements in the electron transfer properties because there is a better environment for biofilm growth due to the changes in surface hydrophobicity. This result is due to the larger number of bacteria attached to the electrode material that act as a bioelectrocatalyst for acetate oxidation. Similar results have been reported by Wu et al. [15] using $\mathrm{NaX}$ zeolite, where after 20 days of inoculation, the authors obtained a current of 1.66 $\mathrm{mA} \mathrm{cm}{ }^{-2}$. Finally, when comparing these results with those obtained by EIS, it is evidenced that at a higher rate of charge transfer (lower faradaic resistance), there are no significant differences in the acetate anion reaction rate with different biofilm thicknesses, indicating that the charge transfer rate is likely to have kinetic and non-resistive control.

Figure 10

\section{CONCLUSIONS}

In this study it was possible to develop an electroactive biofilm on GC/gr- ZYFe behaving as a bioanode. Thereby, the ZY zeolite showed to be a promising material for anode modification for use in MFCs. The $\mathrm{GC} / \mathrm{gr}-\mathrm{ZY}_{\mathrm{Fe}}$ biofilm operating as a bioanode and that of the prepared intermediate electrodes showed that $\mathrm{ZY}$ zeolite is a promising material for anode modification for use in MFCs. Electrodes based on GC/gr-ZY as the anode in MFCs improve the performance compared with the $\mathrm{GC} / \mathrm{gr}$ control. This performance is considerably improved when the ZY in the anode is exchanged with Fe. The rougher surface and the greater reactivity of the bioanodes obtained with $\mathrm{GC} / \mathrm{g}-\mathrm{Z} \mathrm{Y}_{\mathrm{Fe}}$ electrodes were attributed to the zeolite hydrophilicity, the microporous properties of $\mathrm{ZY}$ and the 
improvement of the electrical conductivity of the film by the iron species. The role of the iron species is to improve the efficiency of electron transfer between the bacteria and the anode. The thickness attained over 4 days of biofilm growth allows the anode to degrade the acetate anion. The system works best when the biofilm is grown for 7 days.

More studies are desirable; for example, the role of the hydrophilic/hydrophobic degree of zeolite should be examined. In this pioneering work, we used zeolite with medium hydrophilicity. Finally, the modification used in this study to prepare $\mathrm{ZY}_{\mathrm{Fe}}$-graphite was demonstrated to be an effective and simple approach to improve the bio-current generation of graphite anodes. The low cost and abundance of synthetic and natural zeolites facilitate the development of a larger-scale investigation, such as at a pilot plant, and work is expected to continue in this direction.

\section{Acknowledgments}

This work was supported by the grants CONICYT-PCHA/Doctorado Nacional/2015211160606 from CONICYT (Chile), CONICYT/FONDAP/15130015 and FONDECYT 1140207. 


\section{REFERENCES}

[1] E. Logan, B. Hamelers, R. Rozendal, U. Schröder, J. Keller, S. Freguia, P. Aelterman, W. Verstraete, K. Rabaey, Microbial fuel cells: Methodology and technology, Environ. Sci. Technol.40 (2006) 5181-5192.

[2] Y. Hindatu, M. S. M. Annuar, A. M. Gumel, Mini-review: Anode modification for improved performance of microbial fuel cell, Renew. Sust. Energ. Rev. 73 (2017) 236-248.

[3] F. Li, Y. Sharma, Y. Lei, B. Li, Q. Zhou, Microbial Fuel Cells: The Effects of Configurations, Electrolyte Solutions, and Electrode Materials on Power Generation, Appl. Biochem. Biotechnol. 160 (2010) 168-181.

[4] J. Wei, P. Liang, X. Huang, Recent progress in electrodes for microbial fuel cells, Bioresour. Technol. 102 (2011) 9335-9344.

[5] M. Zhou, M. Chi, J. Luo, H. He, T. Yin, An overview of electrode materials in microbial fuel cells, J. Power Sources. 196 (2011) 4427-4435.

[6] W. Chen, Y.X. Huang, D.B. Li, H.Q. Yu, L. Yan, Preparation of macroporous flexible three-dimensional graphene sponge using an ice-template as the anode material for microbial fuel cells, RSC Adv. 4 (2014) 21619-21624.

[7] G. Mohanakrishna, S.K. Mohan, S.V. Mohan, Carbon based nanotubes and nanopowder as impregnated electrode structures for enhanced power generation: evaluation with real field wastewater, Appl. Energy. 95 (2012) 31-37.

[8] G. Gnana Kumar, C.J. Kirubaharan, S. Udhayakumar, C. Karthikeyan, K.S. Nahm, Conductive Polymer/Graphene Supported Platinum Nanoparticles as Anode Catalyst for the Extender Power Generation of Microbial Fuel Cells, Ind. Eng. Chem. Res. 53 (2014) 1688316893. 
[9] Q. Du, J. An, J. Li, L. Zhou, N. Li, X. Wang, Polydopamine as a new modification material to accelerate startup and promote anode performance in microbial fuel cells, $\mathrm{J}$. Power Sources 343 (2017) 477-482.

[10] J.M. Sonawane, A. Yadav, P.C. Ghosh, S.M. Adeloju, Recent advances in the development and utilization of modern anode materials for high performance microbial fuel cells, Biosens. Bioelectron. 90 (2017) 558-576.

[11] Y. Qiao, X.S. Wu, C.X. Ma, H. He, C.M. Li, A hierarchical porous graphene/nickel anode that simultaneously boosts the bio- and electro-catalysis for high-performance microbial fuel cells, RSC Adv. 4 (2014) 21788-21793.

[12] Y. Fu, J. Yu, Y. Zhang, Y. Meng, Graphite coated with manganese oxide/multiwall carbon nanotubes composites as anodes in marine benthic microbial fuel cells, Applied Surface Science. 317 (2014) 84-89.

[13] C.H. Baerlocher, L.B. Mccusker, D.H. Olson, Atlas of Zeolite framework types, $6^{\text {th }}$ ed, Elsevier (2007).

[14] A. Doménech-Carbó, Theoretical scenarios for the electrochemistry of porous silicatebased materials: an overview, J. Solid State Electrochem. 19 (2015) 1887-1903.

[15] X. Wu, F. Tong, T. Shun, X. Gao, J. Xie, X. Jing, C.C. Zhou, L.X. Zhang, P. Wei, Effect of zeolite-coated anode on the performance of microbial fuel cells, J. Chem. Technol. Biotechnol. 90 (2015) 87-92.

[16] Z. Mojovi, P. Bankovi, N. Jovi-Jovicic, A. Milutinovi-Nikolic, A. Abu Rabi-Stankovi, D. Jovanovic, Electrocatalytic behavior of nickel impregnated zeolite electrode, International Journal of Hydrogen Energy. 36 (2011) 13343-13351.

[17] A. Babaei, M. Zendehdel, B. Khalilzadeh, A. Taheri, Simultaneous determination of tryptophan, uric acid and ascorbic acid at iron (III) doped zeolite modified carbon paste electrode, Colloids Surf B Biointerfaces. 66 (2008) 226-232. 
[18] F. Fernández, C. Berrios, E. Garrido-Ramírez, N. Escalona, C. Gutiérrez, M.S. UretaZañartu, Electrooxidation of 2-chlorophenol and 2,4,6-chlorophenol on glassy carbon electrodes modified with graphite-zeolite mixtures, J. Appl. Electrochem. 44 (2014) 12951306.

[19] M.S. Ureta-Zañartu, M.L. Mora, M.C. Diez, C. Berrios, J. Ojeda, C. Gutiérrez, Chlorophenol electrooxidation on iron oxide-covered aluminosilicates deposited on glassy carbon, J. Appl. Electrochem. 32 (2002) 1211-1218.

[20] E.G. Garrido-Ramírez, M.L. Mora, J.F. Marco, M.S. Ureta-Zañartu, Characterization of nanostructured allophane clays and their use as support of iron species in a heterogeneous electro-Fenton system, Appl Clay Sc. 86 (2013) 153-161.

[21] S. Trasatti, A. Petri, Real Surface Area Measurements in Electrochemistry, Pure and Applied Chemistry. 63 (1991)1-734.

[22] L. Zhang, X. Zhu, J. Li, Q. Liao, D. Ye, Biofilm formation and electricity generation of a microbial fuel cell start up under different external resistances, J. Power Sources. 196 (2011) 967-972.

[23] M. Gracia, J.F. Marco, J. R. Gancedo, W. Exel and W. Meisel, Surface spectroscopic study of the corrosion of ultrathin Fe-57-evaporated and Langmuir-Blodgett films in humid $\mathrm{SO}_{2}$ environments, Surf. Interf. Anal. 29 (2000) 82-91.

[24] V. Crupi, D. Majolino, F. Longo, P. Migliardo, V. Venuti, FTIR/ATR study of water encapsulated in Na-A and Mg-exchanged A-zeolites, Vib. Spectrosc. 42 (2006) 375-380.

[25] L. Ohlin, P. Bazin, F. Thibault-Starzyk, J. Hedlund, M. Grahn, Adsorption of $\mathrm{CO}_{2}, \mathrm{CH}_{4}$, and $\mathrm{H}_{2} \mathrm{O}$ in zeolite ZSM- 5 studied using in situ ATR-FTIR Spectroscopy, J. Phys. Chem. C 117 (2013)16972-16982. 
[26] J. Roy, S. Babanova, K. Garcia, J. Cornejo, L. Ista, P. Atanassov, Catalytic biofilm formation by Shewanella oneidensis MR-1 and anode characterization by expanded uncertainty, Electrochimica Acta. 126 (2014) 3-10.

[27] G. Sun, D. Rodrigues, A. Thygesen, G. Daniel, D. Fernando, A. Meyer, Inocula selection in microbial fuel cells based on anodic biofilm abundance of Geobacter sulfurreducens, Chin. J. Chem. Eng. 24 (2016) 379-387.

[28] X.H. Jiang, J. Petersen, E.R. Fitzgerald, L.A. Jackan, C.S. Lieber, A.M. Ringeisen, C.M. Lieber, J.C. Biffinger, Probing single to multi-cell level charge transport in Geobacter sulfurreducens DL-1, Nat. Commun.4 (2013) 1-6.

[29] Y. Yuan, S.G. Zhou, N. Xu, L. Zhuang, Electrochemical characterization of anodic biofilms enriched with glucose and acetate in single-chamber microbial fuel cells, Colloid Surf. B: Biointerfaces 82 (2011) 641-646.

[30] K.P. Katuri, P. Kavanagh, S. Rengaraj, D. Leech, Geobacter sulfurreducens biofilms developed under different growth conditions on glassy carbon electrodes: insights using cyclic voltammetry, Chem. Commun. 46 (2010) 4758-4760.

[31] E. Marsilli, J. Sun, D.R. Bond, Voltammetry and growth physiology of Geobacter sulfurreducens biofilms as a function of growth stage and imposed electrode potential, Electroanalysis 22 (2010) 865-874.

[32] E. Marsili, D.B. Baron, I.D. Shikhare, D. Coursolle, J.A. Gralnick, D.R. Bond, Shewanella secretes flavins that mediate extracellular electron transfer, Proc. Natl. Acad. Sci. U. S. A. 105 (2008) 3968-3973.

[33] A. Carmona-Martinez, F. Harnisch, L.A. Fitzgerald, J.C. Biffinger, B.R. Ringeisen, U. Schröder, Cyclic voltammetric analysis of the electron transfer of Shewanella oneidensis MR-1 and nanofilament and cytochrome knock-out mutants, Bioelectrochem. 81 (2011) 7480. 
[34] K. Fricke, F. Harnisch, U. Schroder, On the use of cyclic voltammetry for the study of anodic electron transfer in microbial fuel cells, Energ. Environ. Sci. 1 (2008) 144-147.

[35] Y. Liu, F. Harnisch, K. Fricke, R. Sietmann, U. Schröder, Improvement of the anodic bioelectrocatalytic activity of mixed culture biofilms by a simple consecutive electrochemical selection procedure. Biosens. Bioelectron. 24 (2008) 1006-1011.

[36] R. Hartshorne, B. Jepson, T. Clarke, S. Field, J. Fredrickson, J. Zachara, L. Shi, J. Butt, D. Richardson, Characterization of Shewanella oneidensis MtrC: a cell-surface decaheme cytochrome involved in respiratory electron transport to extracellular electron acceptors, J. Biol. Inorg. Chem. 12 (2007) 1083-1094.

[37] R.P. Ramasamy, Z. Ren, M.M. Mench, J.M. Regan, Impact of initial biofilm growth on the anode impedance of microbial fuel cells. Biotechnol Bioeng. 101 (2008) 101-108.

[38] A.P. Borole, D. Aaron, C.Y. Hamilton, C. Tsouris. Understanding long-term changes in microbial fuel cell performance using electrochemical impedance spectroscopy. Environ Sci Technol. 44 (2010) 2740-2744. 


\section{Table Captions}

Table 1. BET surface area and porosity of the unexchanged $(\mathrm{ZY})$ and exchanged $\left(\mathrm{ZY}_{\mathrm{Fe}}\right)$ zeolites.

Table 2. Influence of biofilm growth on different anodes. EIS parameters (average values) from equivalent electrical circuit fitting in $10 \mathrm{mM}$ PBS electrolyte at pH 7.4. 


\begin{tabular}{cccccc}
\hline Zeolite & $\begin{array}{c}\text { BET } \\
\text { area } \\
\left(\mathbf{m}^{\mathbf{2}} \mathbf{g}^{-\mathbf{1}}\right)\end{array}$ & $\begin{array}{c}\text { Porous } \\
\text { Volume } \\
\left(\mathbf{c m}^{\mathbf{3}} \mathbf{g}^{-1}\right)\end{array}$ & $\begin{array}{c}\text { Microporous } \\
\text { Volume } \\
\left(\mathbf{c m}^{\mathbf{3}} \mathbf{g}^{-1}\right)\end{array}$ & $\begin{array}{c}\text { Mesoporous } \\
\text { Volume } \\
\left(\mathbf{c m}^{\mathbf{3}} \mathbf{g}^{-1}\right)\end{array}$ & $\begin{array}{c}\text { Porous diameter } \\
(\mathbf{m m})\end{array}$ \\
\hline $\mathrm{ZY}$ & 764 & 0.34 & 0.34 & 0.0 & 1.50 \\
$\mathrm{ZY}_{\mathrm{Fe}}$ & 258 & 0.18 & 0.14 & 0.04 & 1.57 \\
\hline
\end{tabular}

Table 1 


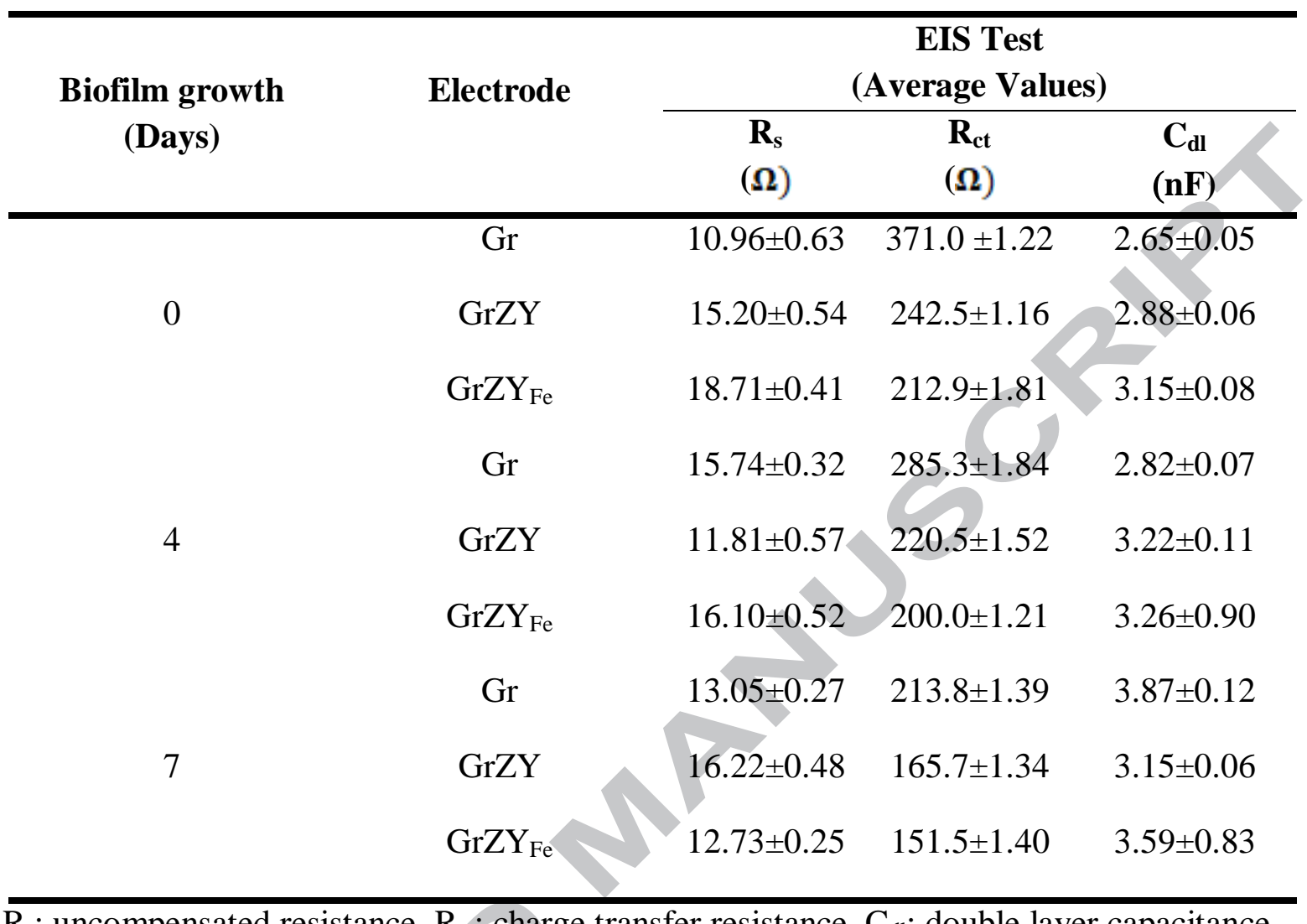

$\mathrm{R}_{\mathrm{s}}$ : uncompensated resistance, $\mathrm{R}_{\mathrm{ct}}$ : charge transfer resistance, $\mathrm{C}_{\mathrm{dl}}$ : double layer capacitance

Table 2

\section{Figure Captions}

Figure 1. SEM micrographs for unexchanged Y zeolite (A) and Fe-exchanged Y zeolite (B).

Figure 2. XPS general spectra: wide-scan spectrum recorded from the original Y zeolite (curve a) and wide-scan spectrum recorded from the Fe-exchanged Y zeolite. XPS spectra of Fe $2 p$ corresponding to the Fe-exchanged $\mathrm{Y}$ zeolite showing the various contributions (inset).

Figure 3. Fourier-transform infrared with Attenuated Total Reflection (FTIR_ATR) spectra for unexchanged Y zeolite (curve a) and Fe-exchanged Y zeolite (curve b).

Figure 4. Voltage output generation during fed-batch MFC operation (biofilm growth) with different electrodes: GC/gr $(\Delta), \mathrm{GC} / \mathrm{gr}-\mathrm{ZY}(\circ)$ and GC/gr-ZYFe (口). 
Figure 5. Current as a function of time $(+0.20 \mathrm{~V}$ vs. $\mathrm{Ag} / \mathrm{AgCl}$ applied potential) of the $\mathrm{GC} / \mathrm{gr}$ (curve a), GC/gr-ZY (curve b) and GC/gr-ZYFe (curve c) electrodes after 7 days of biofilm growth in the presence of $10 \mathrm{mM}$ acetate and electrodes without a biofilm (curve d). The inset is current generation of GC/gr-ZYFe electrode with biofilm after 2 days.

Figure 6. SEM micrographs of electrodes before microbial colonization: (A) GC/gr, (B) GC/gr-ZY, (C) GC/gr-ZY ${ }_{\mathrm{Fe}}$. After 7 days of MFC operation: (D) GC/gr, (E) GC/gr-ZY and (F) $\mathrm{GC} / \mathrm{gr}-\mathrm{ZY} \mathrm{Fe}$.

Figure 7. Cyclic voltammetry at $5 \mathrm{mV} \mathrm{s}^{-1}$ in $10 \mathrm{mM} \mathrm{PBS}$ at $\mathrm{pH} 7.4$ using different electrodes with a biofilm (thick line) and without a biofilm (thin line). (A) GC/gr, (B) GC/gr-ZY, and (C) $\mathrm{CC} / \mathrm{gr}-\mathrm{ZY} \mathrm{Fe}$.

Figure 8. Effect of the biofilm growth time on the EIS behavior of $₫ \mathrm{GC} / \mathrm{gr}$, $\bullet \mathrm{GC} / \mathrm{gr}-\mathrm{ZY}$ and $\Delta \mathrm{GC} / \mathrm{gr}-\mathrm{ZY}_{\mathrm{Fe}}$ anodes in $50 \mathrm{mM}$ PBS electrolyte: (A) before microbial colonization and at (B) 4 days and (C) 7 days. Applied potential $=-0.082 \mathrm{~V}$.

Figure 9. Randles equivalent circuit.

Figure 10. Cyclic voltammograms at $5 \mathrm{mVs}^{-1}$ in a $10 \mathrm{mM}$ acetate solution using different electrodes without (inset) and with a biofilm: (1) GC/gr, (2) GC/gr-ZY and (3) GC/gr-ZY Fe. 

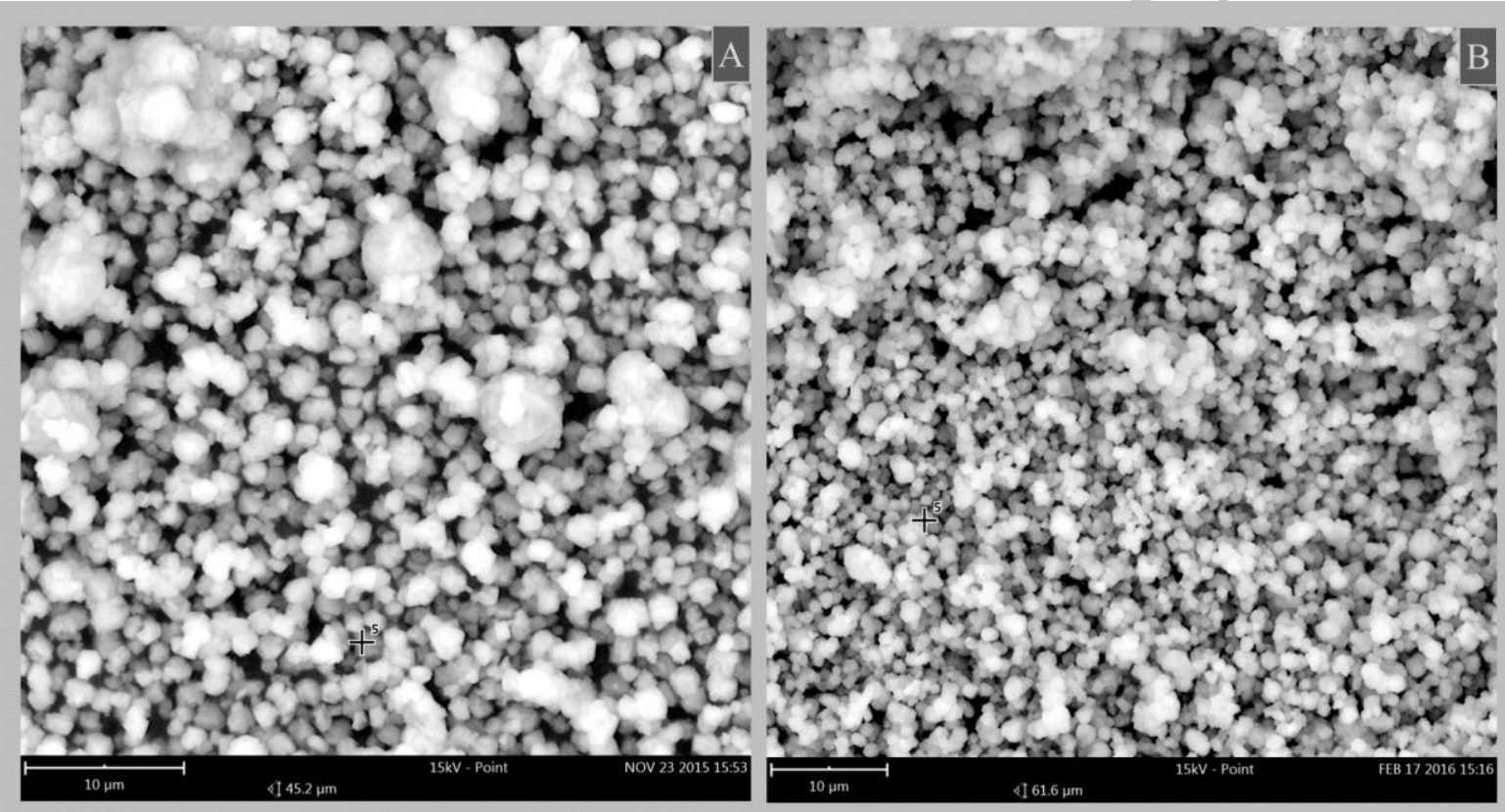

Figure 1 


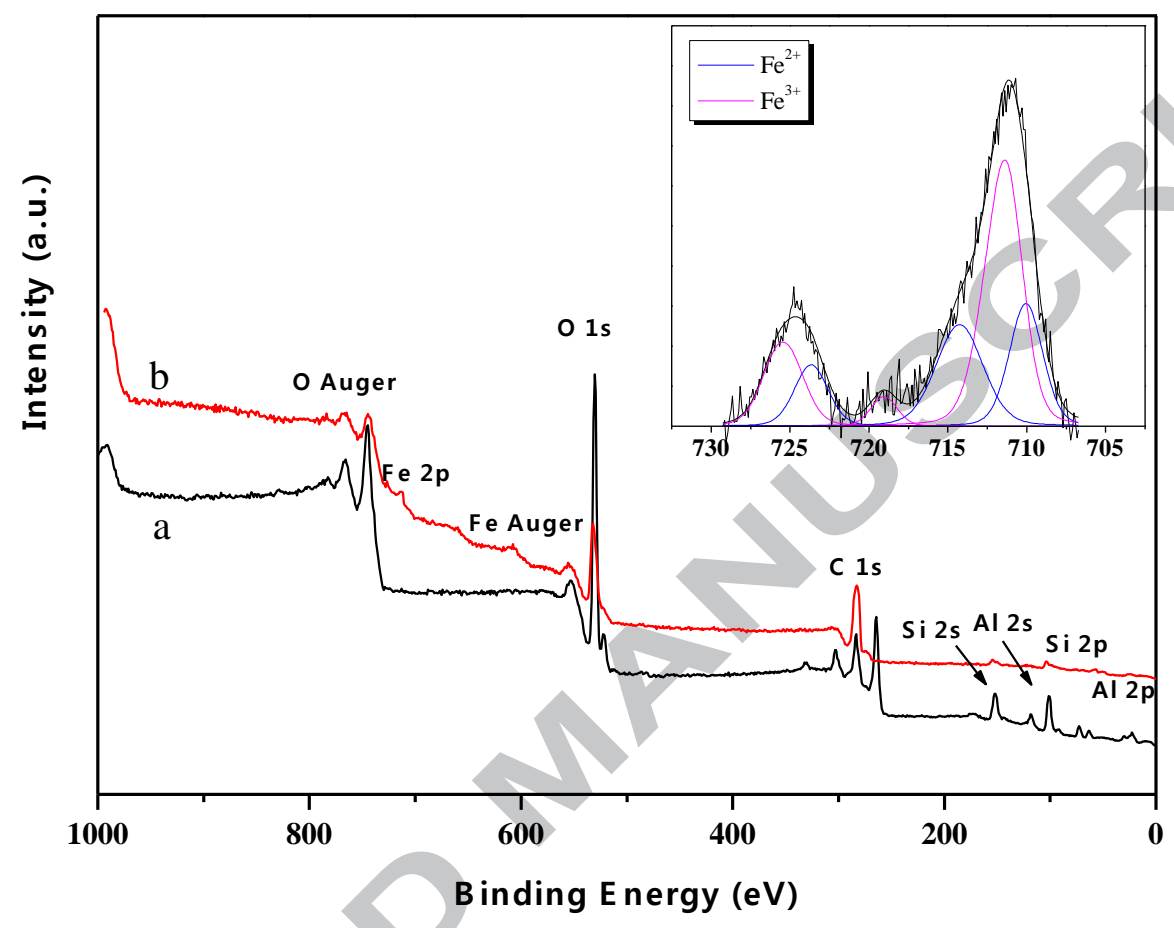

Figure 2 


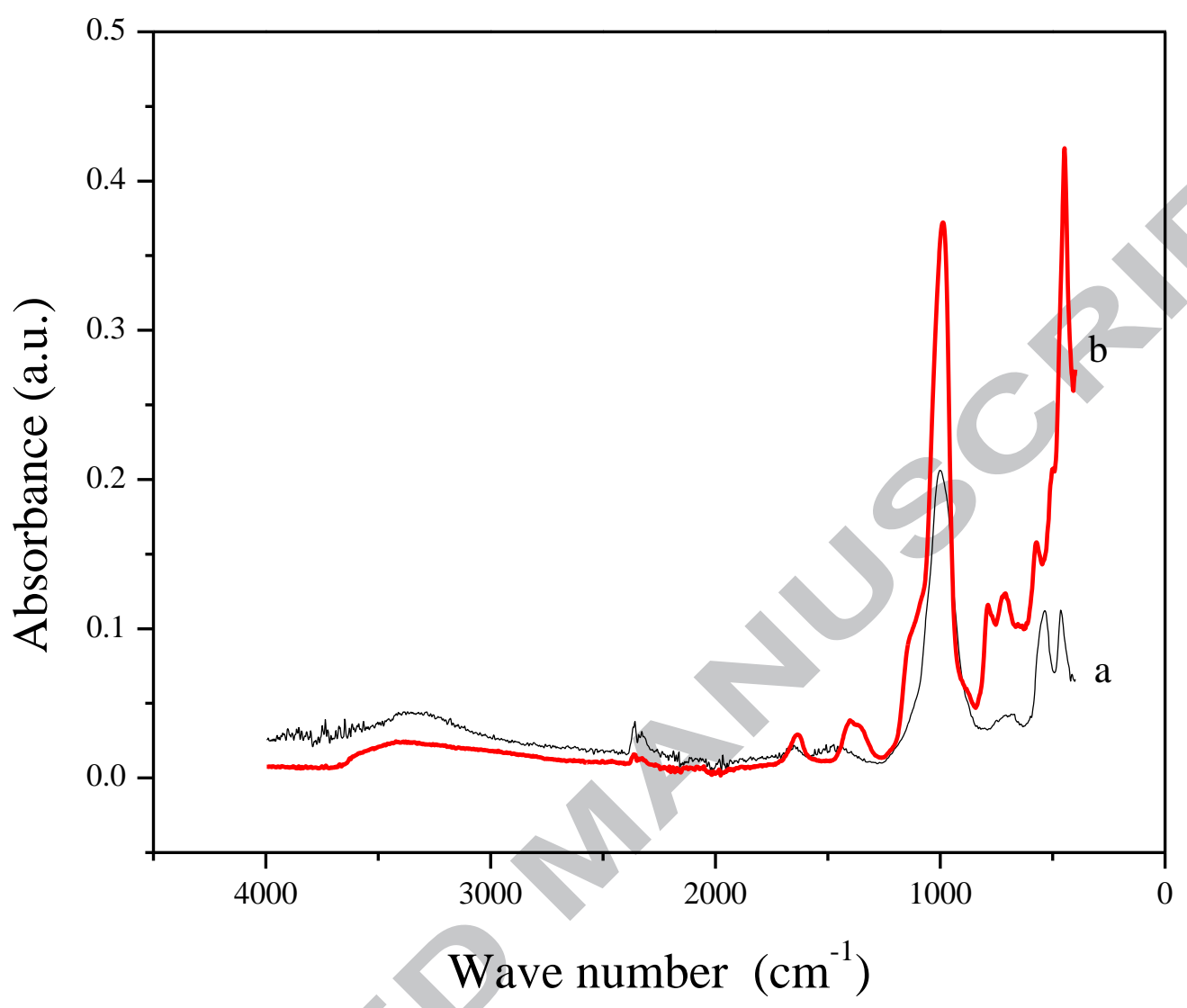

Figure 3 


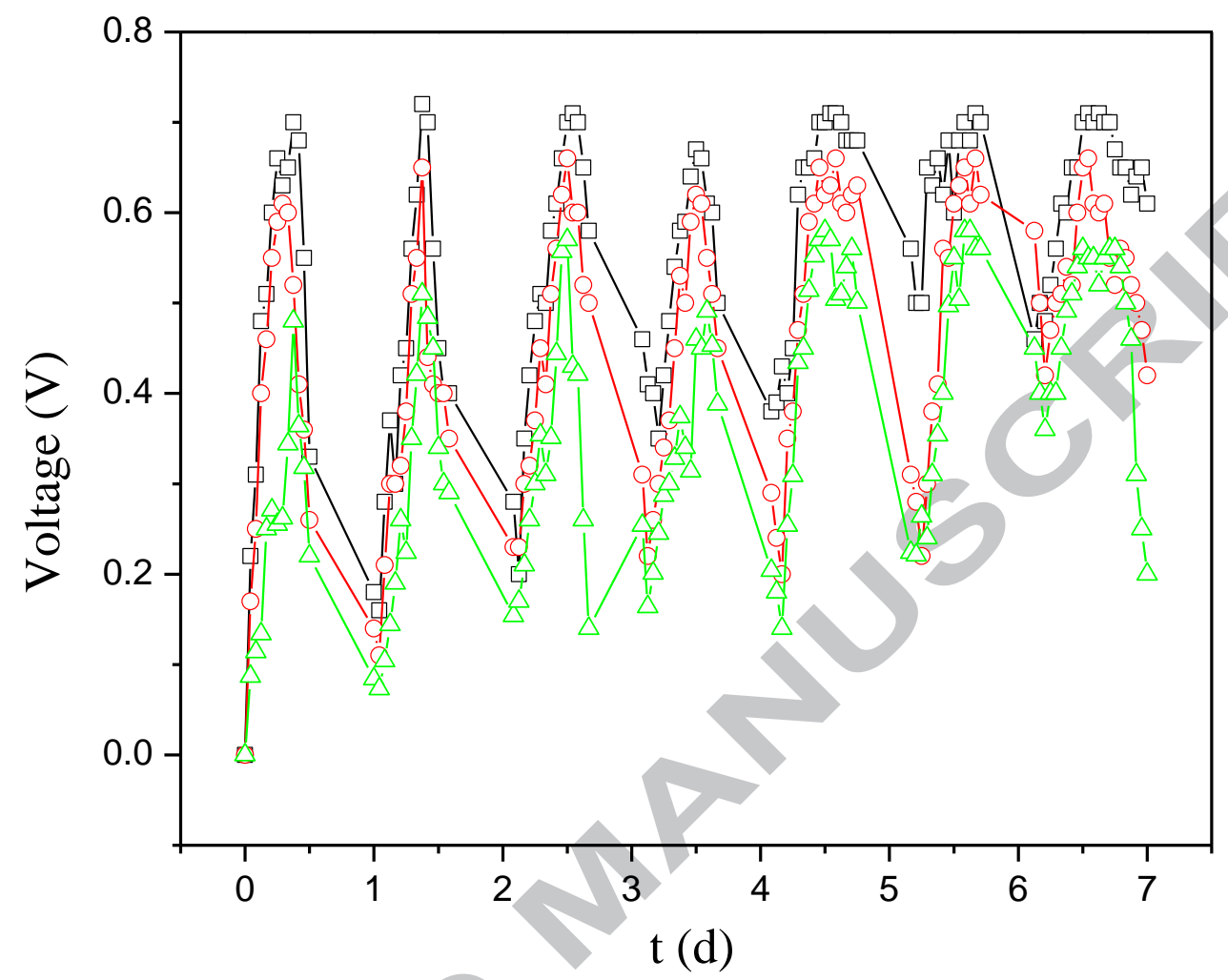

Figure 4 


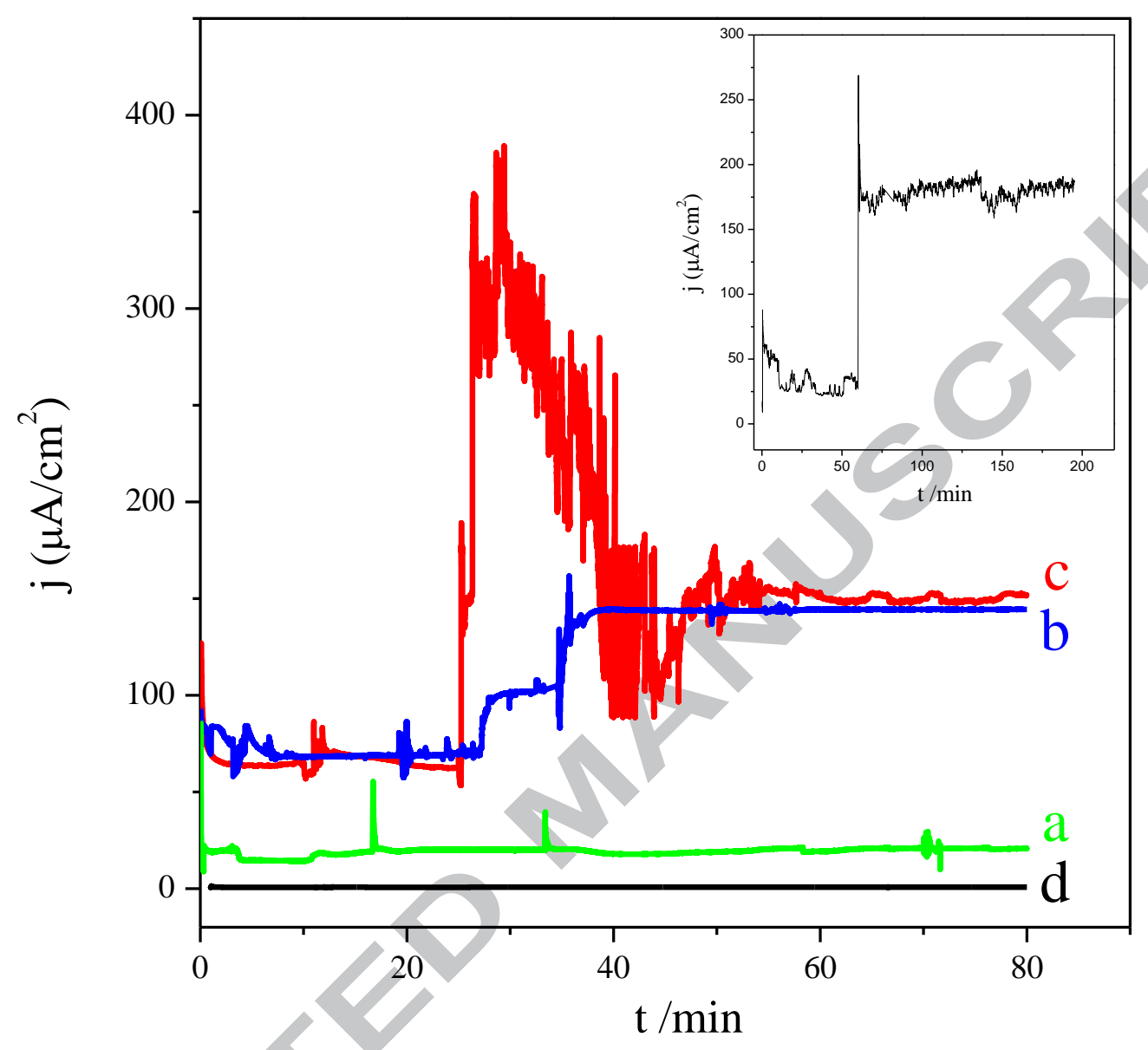

Figure 5 


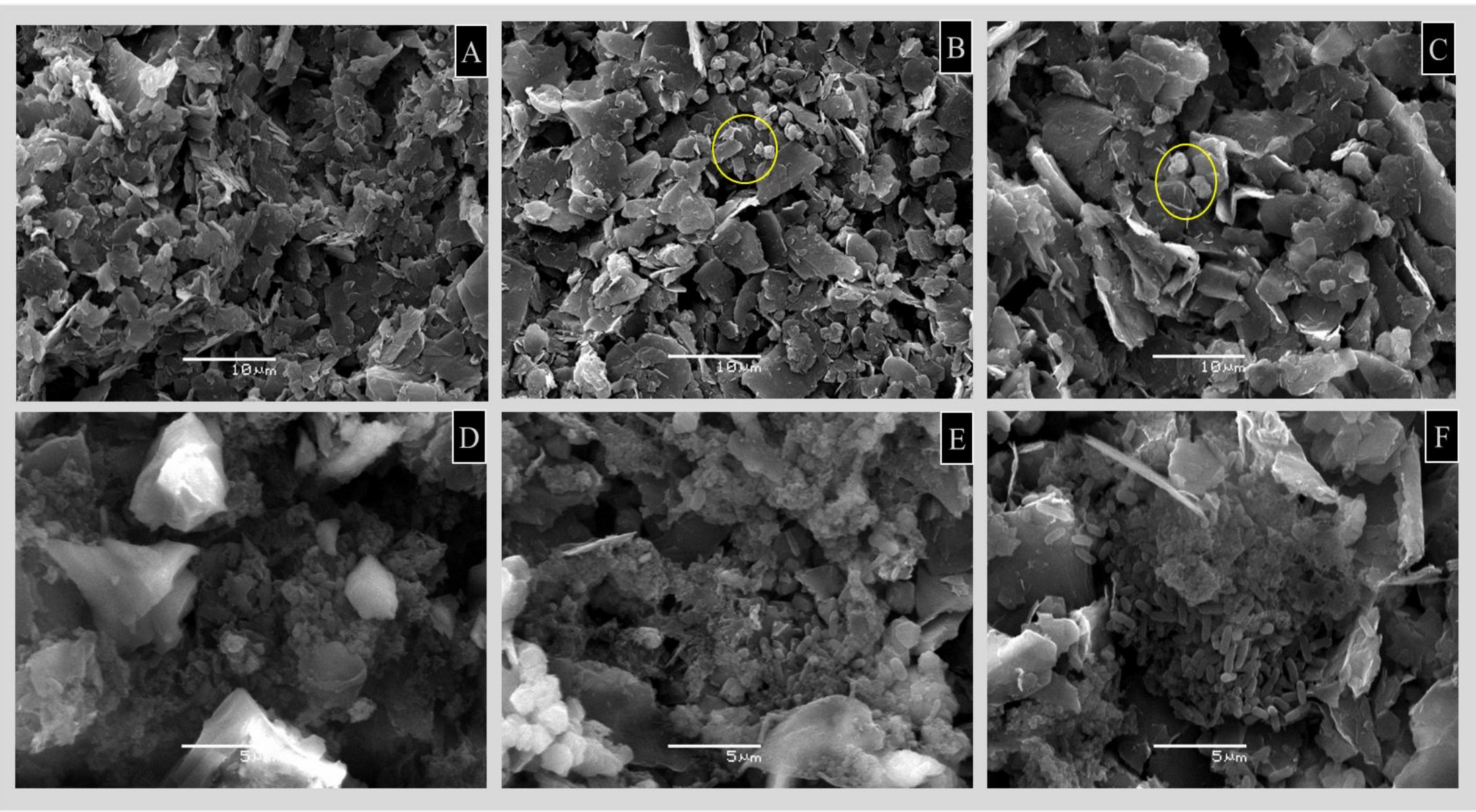

Figure 6 

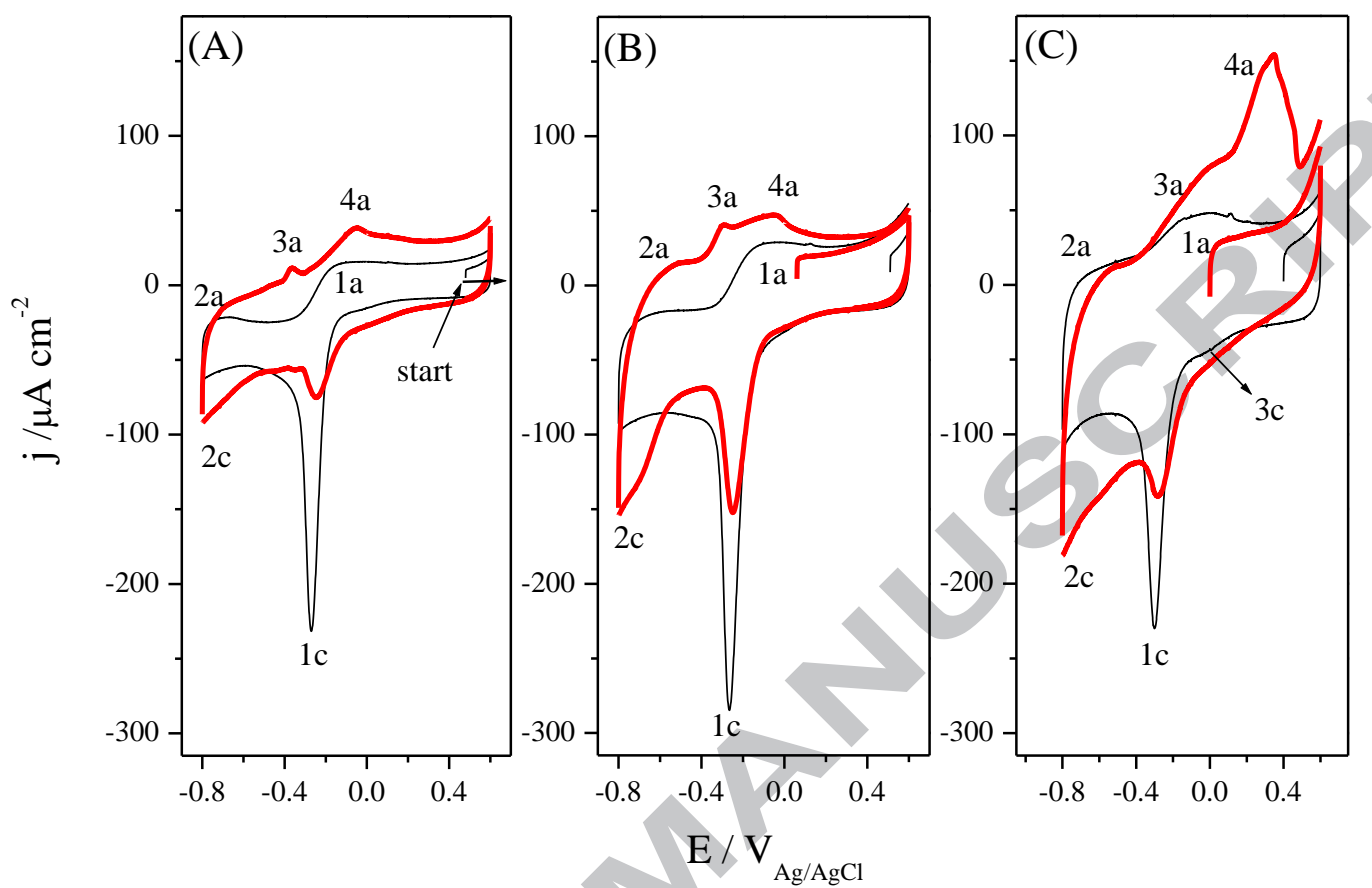

Figure 7 

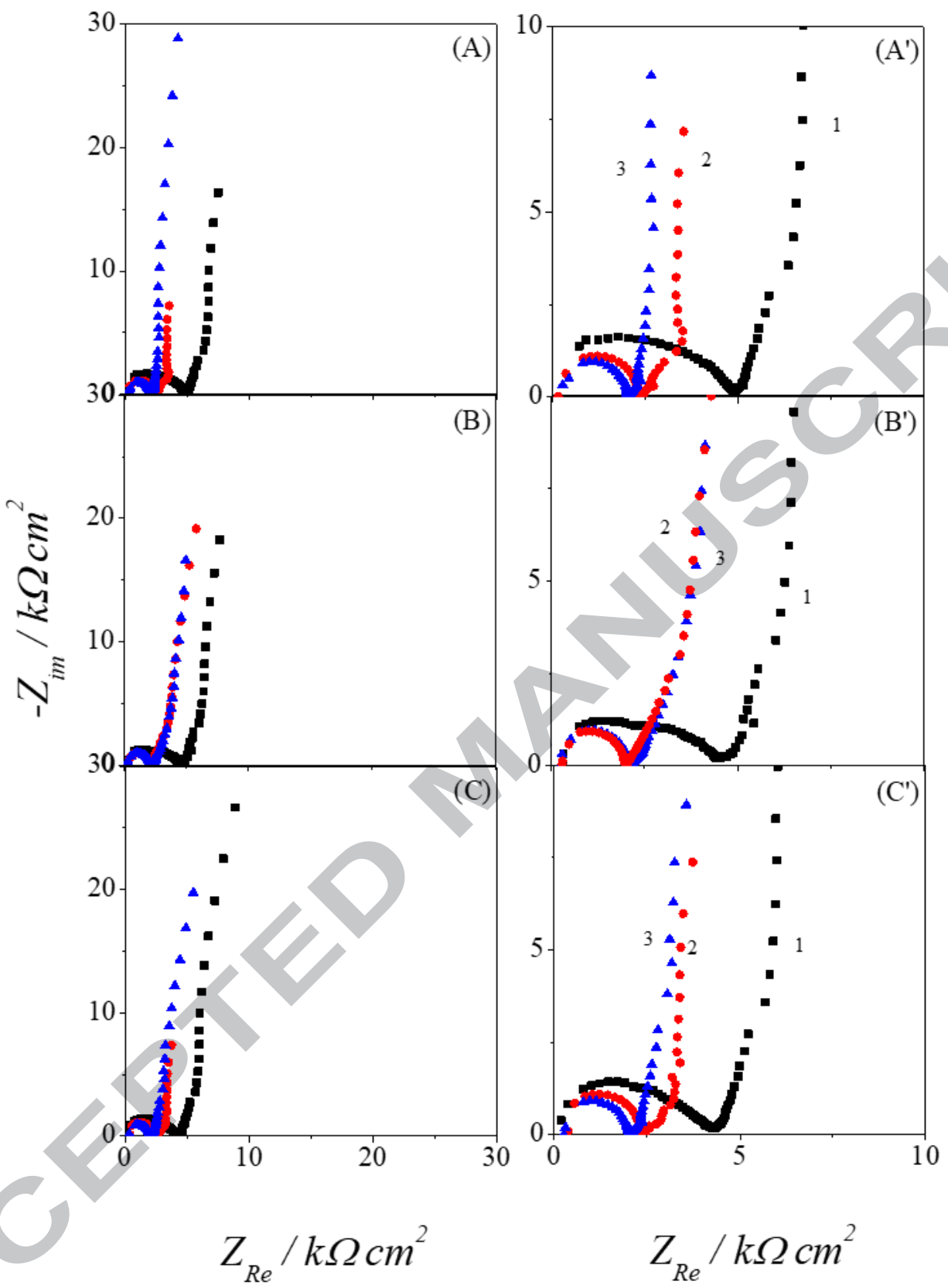

Figure 8 


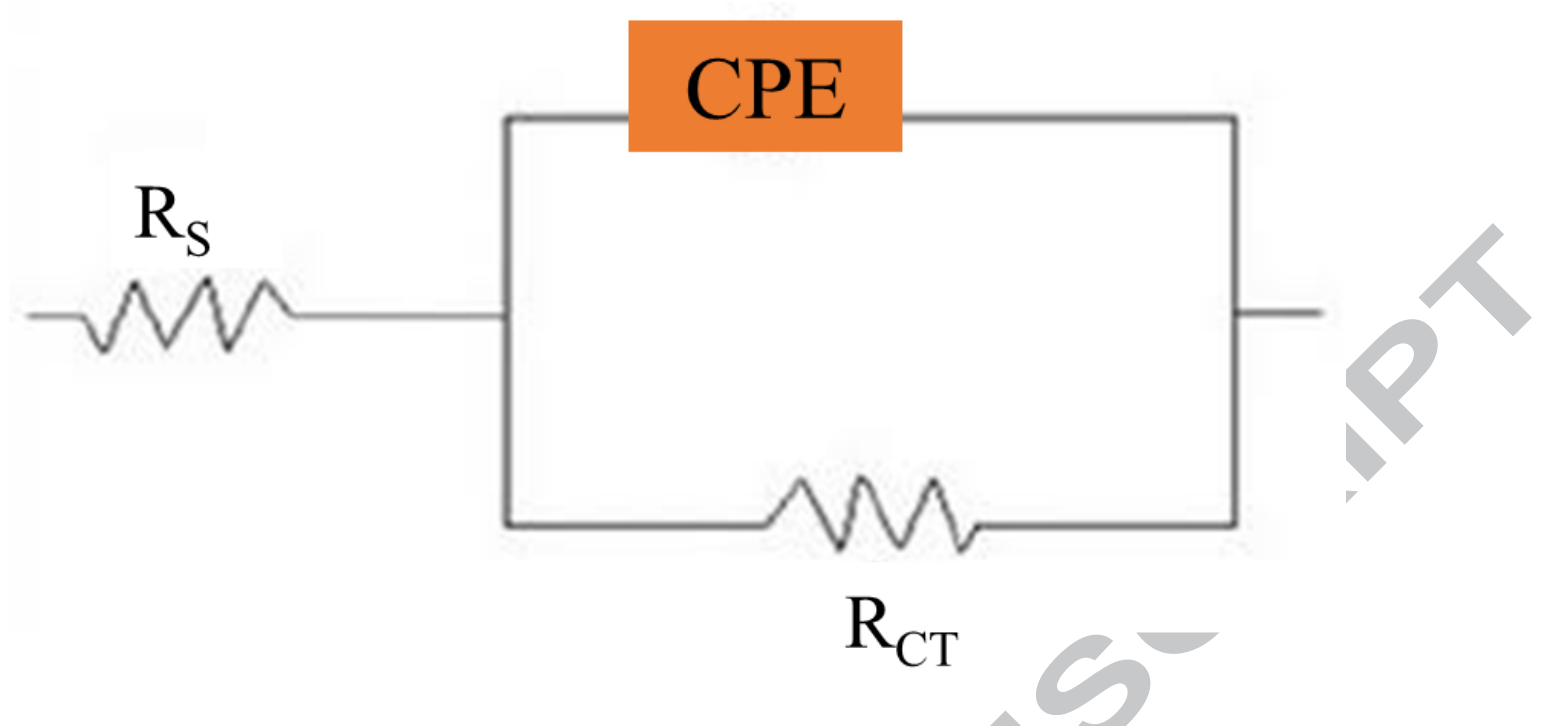

Figure 9 


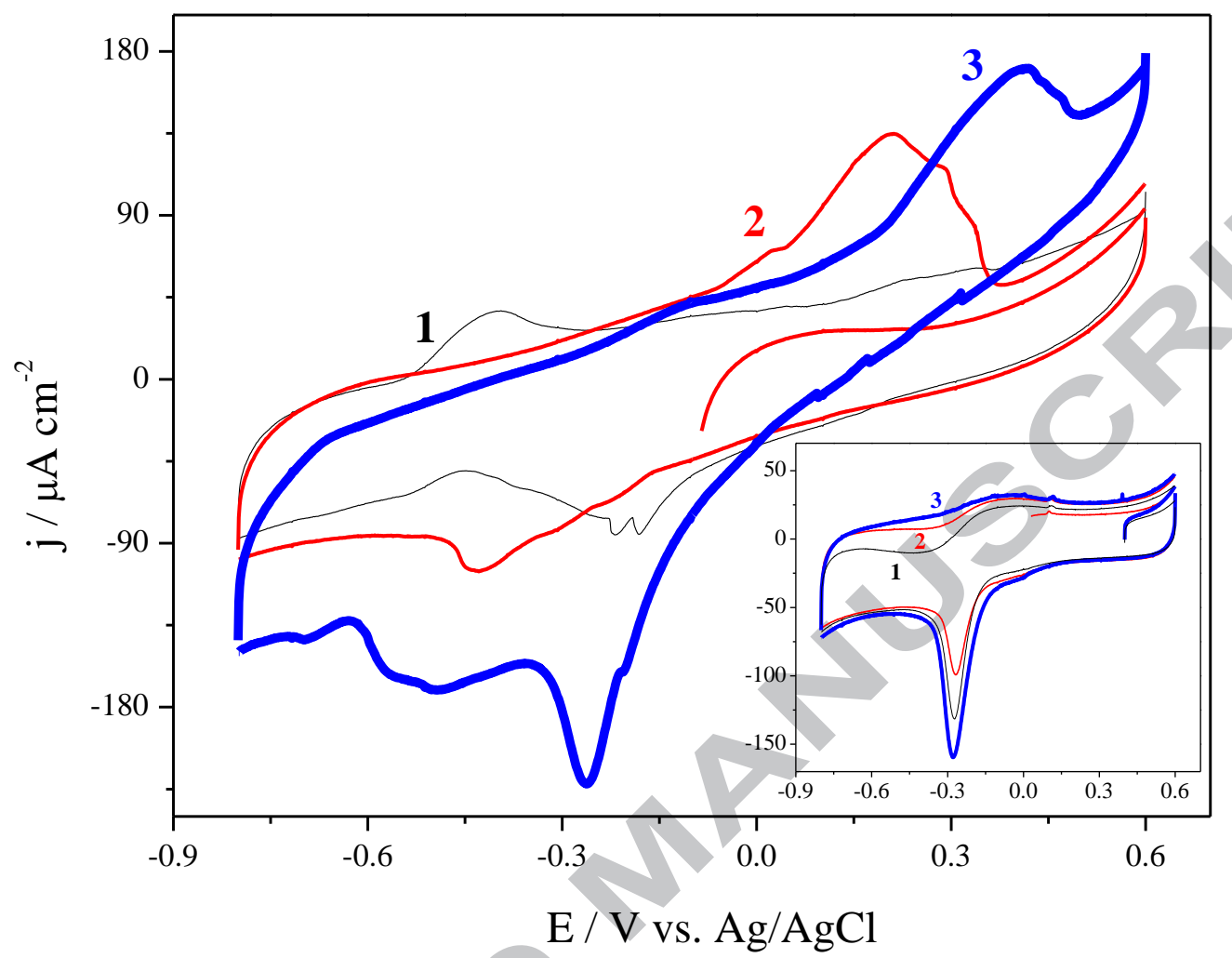

Figure 10 


\section{Highlights}

- Glassy carbon electrode is modified with a dispersion of $Y$ zeolite and graphite.

- Zeolite changes the electrode surface hydrophobicity favoring the growth of a biofilm.

- The modified anodes have an electroactive biofilm with electrochemical activity for acetate oxidation.

- The presence of Fe species promotes electron transfer properties of anode. 